\title{
Does the decline of red wood ants after clear-cutting favour epigeic arthropods?
}

\author{
MichAŁ ŻMIHORSKI \\ Museum and Institute of Zoology, Polish Academy of Sciences, Wilcza 64, 00-679 Warsaw, Poland; \\ e-mail: zmihorski@miiz.waw.pl
}

Key words. Hymenoptera, Formica, predation, competition, forest management, clear-cuts, intra-guild predation

\begin{abstract}
In forest ecosystems in the temperate and boreal zones in Europe, red wood ants (RWA, Formica rufa group) have a significant affect as predators and competitors in communities of ground-dwelling arthropods. Therefore, the spatiotemporal distribution and abundance of RWA affect the distribution of many other species. The hypothesis that a reduction in the abundance of RWA in clear-cut areas enables other arthropods to increase in abundance was tested. The study was conducted in NW Poland in 2007 and 2008. A total of $2761 \times 1 \mathrm{~m}$ plots were sampled and 1,696 individuals recorded. The probability of the occurrence of RWA decreased significantly towards the center of clear-cut areas and increased with increasing plant cover. The frequency of Lasius platythorax, Formica fusca and spiders in the plots significantly increased towards the edge of a clear-cut area. Moreover, the occurrence of $L$. platythorax was negatively associated with the presence of RWA, while that of the Myrmica species was positively associated. The effect of the distance to the edge of a clear-cut area seems to be much more pronounced than the effect of RWA. This suggests that the arthropods studied prefer habitats close to the edge that are utilized by RWA than RWA-free sites located in the centre of clear-cut areas.
\end{abstract}

\section{INTRODUCTION}

Several species of ants belonging to the Formica rufa (L., 1761) group (the red wood ants) have a significant role in communities of ground-dwelling invertebrates in forest ecosystems of the temperate and boreal zones in Europe. The high biocenotic importance of these ants is because they are territorial, effective predators and strong competitors in communities of ground-dwelling invertebrates (Koivula \& Niemelä, 2003; Atlegrim, 2005). Moreover, many ant species belonging to the genus Formica (L., 1758) are abundant; for example colonies of Formica polyctena (Förster, 1850) can be made up of many millions of workers (Czechowski et al., 2002). Territorial and aggressive behaviour of the ants, combined with their high abundance, makes them one of the most important components of the forest ecosystem. As a consequence, spatiotemporal distribution and abundance of red wood ants is of great importance for inter-specific interactions within invertebrate communities, and may affect the distribution of many other species, including myrmecophilous specialists, as well as the fitness of some vertebrates, development of the plant cover, nutrient cycles etc (Reznikova \& Dorosheva, 2004; Dorosheva \& Reznikova, 2006; Jäntti et al., 2007; Kilpeläinen et al., 2008; Lambrechts et al., 2008). This in turn affects community stability, the existence of forest ecosystems and co-evolution of sympatric species (Pisarski \& Vepsäläinen, 1989; Atlegrim, 2005; Geiselhardt et al., 2007; Servigne \& Detrain, 2008).

However, most forested areas in the temporal and boreal zones are managed for timber production. Forest management significantly alters spatiotemporal characteristics of an ecosystem, such as when part of a forest is clear-cut (Linder \& Östlund, 1998; Wesołowski, 2005).
The effect of forest management on the biology of a particular species may in turn change the inter-specific interactions between species inhabiting transformed ecosystems. This indirect effect of man-made forest transformation is not well understood, but it seems that the process may play an important role in the conservation of forest biodiversity, especially when it affects keystone species or changes symbiosis- or mutualism-like interactions among taxa. In general, clear-cutting and deforestation affect red wood ants negatively (Sorvari \& Hakkarainen, 2005, 2007) as the area occupied by Formica species decreases following clear-cutting (Sorvari \& Hakkarainen, 2007; Żmihorski, 2010).

Bearing in mind the high biocenotic importance of red wood ants, one may expect that the reduction in their abundance after forest clearing would have great ecological consequences for the ecosystem. Therefore, the aim of this paper was to explore the consequences of clear cutting areas of forest. The hypothesis proposed is that the reduction in the numbers of red wood ants in clear-cut areas of forest enables other invertebrates, including other ants, to increase in numbers. If this is the case then both the species richness and species diversity of invertebrates will increase towards the centre of clearcuts areas that remain ant-free.

\section{MATERIAL AND METHODS}

\section{Study area}

This study was conducted in Western Poland $\left(52^{\circ} 48^{\prime} \mathrm{N}\right.$; $14^{\circ} 20^{\prime} \mathrm{E}$ ), in a large forest complex (ca. 14,000 ha) managed by the National Forest Holding. The stand of trees was dominated by Scots pine (Pinus sylvestris), with a considerably lower proportion of oaks (Quercus spp.) and birch (Betula pendula). The forest consists of semi-rich and poor habitats, with sandy soils and the understorey vegetation dominated by mosses (Polytri- 
chum spp.), grasses (Calamagrostis spp., Deshampsia flexuosa) and shrubs (Rubus spp., Vaccinium vitis-idaea). Clear-cutting is the preferred method of harvesting timber. Plant cover on the clear-cut areas was composed mainly of Calamagrostis epigejos, Convolvulus arvensis, Rubus idaeus, Senecio vulgaris and Dryopteris carthusiana. Stand age varied greatly, ranging from 0 years on freshly clear-cut areas to $100-150$ years in the oldest patches.

\section{Sampling method}

Ants, carabids and spiders were sampled in six clear-cut areas in spring and summer (30 $30^{\text {th }}$ May-20 $0^{\text {th }}$ August) of 2007 and 2008. The areas were clear cut up to 2 years before they were sampled and did not differ in terms of habitat, which was fresh and moderately rich. On each clear-cut area transects were established, along which ca. $151 \times 1 \mathrm{~m}$ plots were sampled. Each transect started at the edge of a clear-cut area (close to the intact, oldgrowth forest) and ended about $30 \mathrm{~m}$ from the edge (up to $40 \mathrm{~m}$ in the case of the longest transect). The plots that were to be sampled were marked with a wooden frame and placed $1 \mathrm{~m}$ apart from one another. In each plot, Red Wood Ants, Formica fusca (L., 1758), Lasius spp. (Fabricius, 1804), Tetramorium caespitum (L., 1758) and Myrmica spp. (Latreille, 1804) were counted over a period of 1-3 min. All individuals present in the plot, as well as those entering the plot during counts, were included. In the case of Lasius spp. the species was not identified, but it was assumed on the basis of former research (Włodarczyk et al., 2009) that they were L. platythorax (Seifert, 1991). The species of RWA were also not identified as it was assumed that all species belonging to this group are ecologically similar and have similar roles in the community of epigeic invertebrates. The numbers of other ant species (e.g. Leptothorax spp. (Mayr, 1855), Camponotus spp. (Mayr, 1861)) were also recorded, but because of their low abundance they were not included in the final analysis. At each plot carabid beetles and ground-dwelling spiders (web spinning spiders were not included) were also counted. This gave an indication of the numbers of each species or species/group present at a particular time (hereafter referred to as density) in all the plots. In addition, the percentage of plant cover in each plot was assessed in terms of whether it was a potential factor influencing the number of ants, carabids and spiders. All counts were made when the weather conditions were good, but not at midday when insolation is greatest.

\section{Statistical analysis}

In total, data from 276 plots were included in the analysis. First, a detrended correspondence analysis (DCA) implemented in CANOCO software (Lepš \& Šmilauer, 2003) was used to visualize simple co-occurrences between the arthropods. The analysis was supplemented with Chi-square tests used for testing the significance of co-occurrences for each pair of species $(2 \times 2$ contingency tables in each case). Next, the redundancy analysis (RDA) implemented in CANOCO was used as a tool for linking distribution and abundance of particular species in the plots with habitat characteristics. The proximity to the edge of a clear-cut area, plant cover and the presence of red wood ants were used as the three explanatory variables in the RDA, whereas year, compartment and transect were used as covariables. In addition, the variability in the number of species per plot and variability in the number of individuals per plot were plotted along the first two axes of RDA using general additive models (GAM). This enabled inferences to be made about the relationship between the two values and the three explanatory variables. Finally and most importantly, a generalized linear mixed model (GLMM, Bolker et al., 2009) was used to explore the effect of distance to the edge, plant cover and presence of red wood ants on the presence of each of the six species / group of species of arthropods. For this purpose, the "Imer" function from "Ime4" package in the R program (R Development Core Team, 2009) was used. For each of the six species / group of species, a GLMM with binomial error distribution and logit link function, in which their presence (present vs. absent) was the dependent variable, was performed. The year, compartment and transect were included in the model as random categorical factors in the nested design (transect was nested in compartment, which in turn was nested in year), whereas distance to the edge and plant cover were covariates and presence of red wood ants was a fixed categorical factor. Only significant variables were included in the final models. Likelihood-ratio chi-square tests and Akaike's information criterion (AIC) were used to compare a given model with a model containing intercept and random factor-only.

\section{RESULTS}

In total, 1,696 ground arthropods were recorded at 253 of the 276 plots. The pooled number of invertebrates per plot ranged from 0 to 52 individuals $(6.14 \pm 7.054 \mathrm{SD}$ on average). Myrmica spp., spiders, Lasius platythorax and red wood ants were the most abundant species/groups (446, 328, 268 and 251 individuals recorded, respectively).

Analysis of the co-occurrence of ground dwelling arthropods revealed that Formica fusca co-occurred significantly more often than expected by chance with red wood ants and with Lasius platythorax. Also Myrmica spp. shared plots with this species more often than expected (Fig. 1). In total, four pairs of species cooccurred more often than expected by chance, whereas another four showed the opposite tendency (Fig. 1).

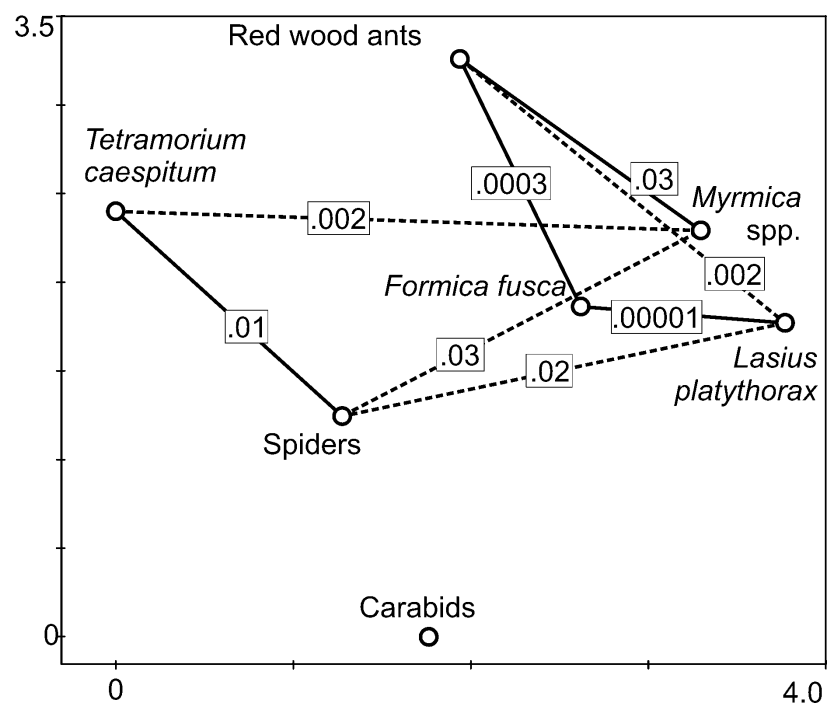

Fig. 1. Distribution of the arthropods studied along the two first axes of the detrended correspondence analysis (DCA). Pairs of species that significantly co-occurred are linked by solid lines and those that significantly avoided each other are linked by dashed lines. Co-occurrence and avoidance were tested using $\chi^{2}$ tests ( $\mathrm{df}=1$ in each case), $\mathrm{p}$-values of the test (without leading zeros) are shown in the boxes. 


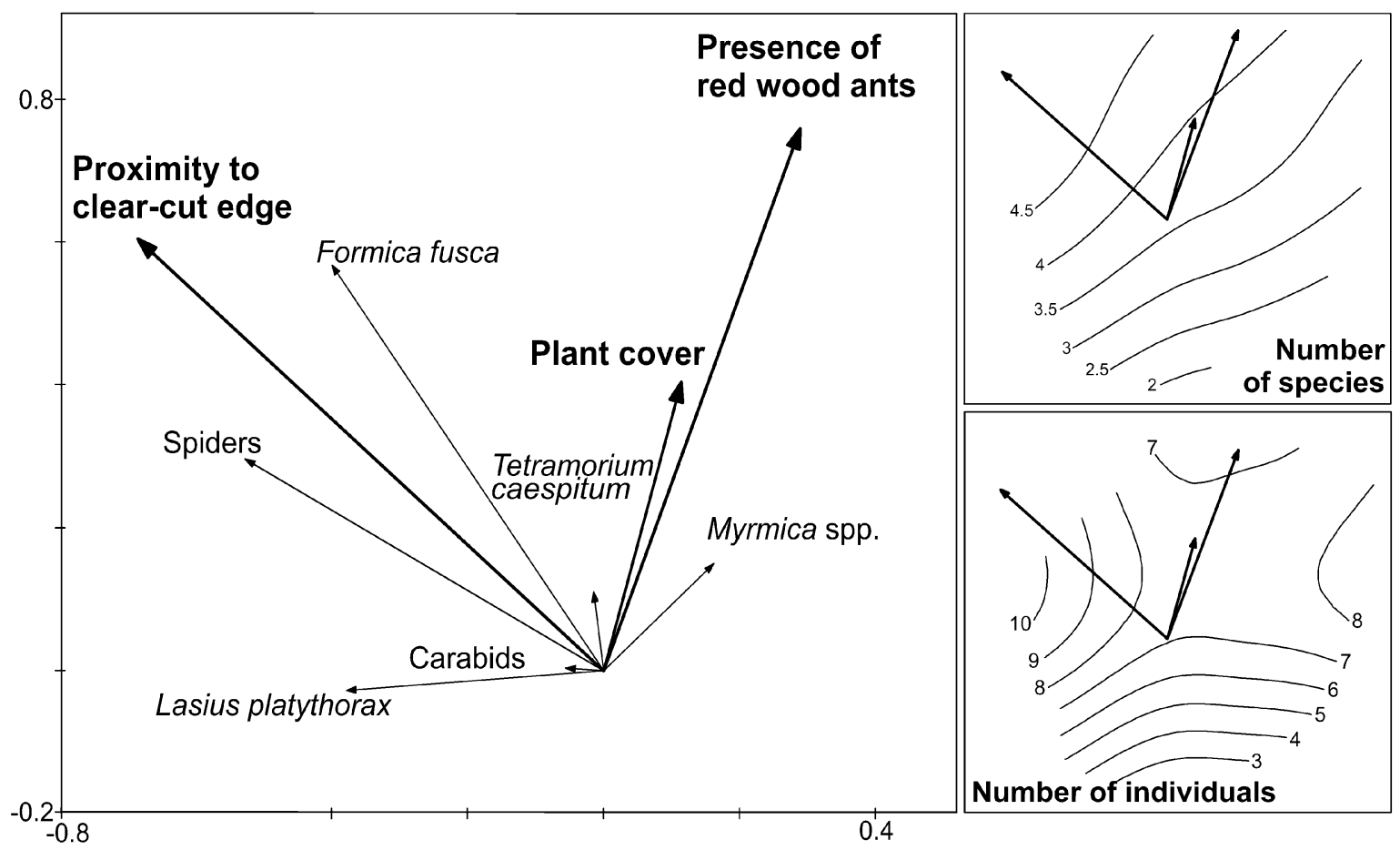

Fig. 2. Redundancy analysis (RDA) biplot with the vectors of the arthropods studied and explanatory variables along the first two axes. Year, clear-cut and transect are used as covariables. Attribute plots showing the variability in the number of species and number of individuals in the samples (presented as isolines, fitted using general additive models) are presented in the smaller subplots along with vectors of the explanatory variables.

The redundancy analysis showed that the distribution of spiders, carabids and Formica fusca was related mainly to the proximity of the edge of a clear-cut area. Lasius platythorax avoided plots settled by red wood ants. The presence of Tetramorium caespitum and Myrmica spp. seemed to be unrelated to the predictors studied. The pooled number of species increased with increasing plant cover and red wood ant abundance, whereas it seemed to be independent of the proximity to the edge of a clear-cut area. The pattern in the number of individuals of all arthropods recorded is less clear, however, there is an indication that there is an increase with decreasing distance from the edge of a clear-cut area (Fig. 2).

The generalized linear mixed models showed that the presence of RWA was positively associated with plant cover and negatively associated with the distance to the edge of a clear-cut area (Table 1). In the case of the remaining arthropods, different explanatory variables are associated with the presence of particular species recorded in the plots. Distance to the edge of a clear-cut area was negatively associated with the probability of occurrence of Lasius platythorax, Formica fusca and spiders, and no positive association with this variable was recorded (Fig. 3, Table 1). The presence of red wood ants was negatively associated with the occurrence of Lasius platythorax and spiders (nearly significant), and positively with Myrmica species. The distribution of Tetramorium caespitum in the plots was positively associated with plant cover.

\section{DISCUSSION}

A disadvantage of this study is that the species of red wood ants, Myrmica, spiders and carabids were not identified. However, this approach can be partially justified by the fact that the species pooled within each group have a similar role in the whole community, and the ecological differences (and taxonomic distance) among the species within groups are lower than between groups. Moreover, using this approach it was not necessary to kill the animals in order to identify them, which should also be taken into account. Nevertheless, because the results for the species were pooled, the results and conclusions are general and not necessarily valid for a particular species included in a given group.

The effect of the presence of red wood ants on the distribution of other ants and arthropods in clear-cut areas is difficult to investigate, since RWA numbers are significantly affected by clear-cutting (Punttila et al., 1996; Sorvari \& Hakkarainen, 2005, 2007). Therefore, in order to correct for this, it is necessary to include both the effect of RWA and disturbance in any such study, otherwise, the effect of clear-cutting on RWA may lead to inappropriate inferences.

A simple analysis of the co-occurrence of ground dwelling arthropods revealed some unexpected relationships. Most interestingly, $F$. fusca was present significantly more often in plots with RWA than in RWA-free plots. Interestingly, in the case of $F$. fusca, positive cooccurrence was noted also with L. platythorax. Similar relationships of $F$. fusca with other ant species were recorded previously in the same forest complex 
TABLE 1. Summary of the generalized linear mixed models (GLMM) with binomial error distribution and logit-link function explaining occurrences of the epigeic arthropods studied in relation to distance to the edge of a clear-cut area, plant cover and presence of red wood ants. Only significant or nearly significant predictors were included in the models. For each model two criteria were used to compare a given model with a model containing intercept- and random factors-only: likelihood ratio chi-square test and Akaike's information criterion scores (negative $\triangle \mathrm{AIC}$ values indicate worse fit by intercept- and random factors-only model relative to a given model).

\begin{tabular}{|c|c|c|c|}
\hline Predictor & $\operatorname{Exp}(B)$ & $\mathrm{Z}$ & $\mathrm{P}$ \\
\hline \multicolumn{4}{|l|}{ Lasius platythorax } \\
\hline \multicolumn{4}{|c|}{$\chi^{2}=19.2 ; \mathrm{df}=2 ; \mathrm{p}=0.0001 ; \Delta \mathrm{AIC}=-15.4$} \\
\hline Intercept & 0.967 & -0.05 & 0.9634 \\
\hline Distance & 0.843 & -3.77 & 0.0001 \\
\hline Red wood ants & 0.177 & -2.78 & 0.0055 \\
\hline \multicolumn{4}{|c|}{ Formica fusca } \\
\hline \multicolumn{4}{|c|}{$\chi^{2}=23.2 ; \mathrm{df}=1 ; \mathrm{p}<0.0001 ; \Delta \mathrm{AIC}=-21.2$} \\
\hline Intercept & 0.582 & -1.21 & 0.2280 \\
\hline Distance & 0.821 & -4.54 & 0.0000 \\
\hline \multicolumn{4}{|c|}{ Myrmica spp. } \\
\hline \multicolumn{4}{|c|}{$\chi^{2}=6.6 ; \mathrm{df}=1 ; \mathrm{p}=0.0102 ; \Delta \mathrm{AIC}=-4.6$} \\
\hline Intercept & 0.448 & -1.50 & 0.1339 \\
\hline Red wood ants & 2.449 & 2.57 & 0.0103 \\
\hline \multirow{2}{*}{\multicolumn{4}{|c|}{$\begin{array}{l}\text { Tetramorium caespitum } \\
\chi^{2}=3.5 ; \mathrm{df}=1 ; \mathrm{p}=0.0614 ; \Delta \mathrm{AIC}=-1.5\end{array}$}} \\
\hline & & & \\
\hline Intercept & 0.050 & -5.04 & 0.0000 \\
\hline Plant cover & 1.064 & 2.04 & 0.0416 \\
\hline \multicolumn{4}{|l|}{ Spiders } \\
\hline \multicolumn{4}{|c|}{$\chi^{2}=8.4 ; \mathrm{df}=2 ; \mathrm{p}=0.0150 ; \Delta \mathrm{AIC}=-4.6$} \\
\hline Intercept & 2.123 & 1.04 & 0.2972 \\
\hline Distance & 0.507 & -1.82 & 0.0681 \\
\hline Red wood ants & 0.908 & -2.86 & 0.0042 \\
\hline \multirow{2}{*}{\multicolumn{4}{|c|}{$\begin{array}{l}\text { Red wood ants } \\
\chi^{2}=48.0 ; \mathrm{df}=2 ; \mathrm{p}<0.0001 ; \Delta \mathrm{AIC}=-44.1\end{array}$}} \\
\hline & & & \\
\hline Intercept & 0.400 & -1.17 & 0.2405 \\
\hline Distance & 0.732 & -5.61 & 0.0000 \\
\hline Plant cover & 1.073 & 2.79 & 0.0053 \\
\hline
\end{tabular}

(Włodarczyk et al., 2009) and in Finland (Väänänen et al., 2010). As with F. fusca, the Myrmica species were more abundant when RWA were present. Since the positive co-occurrence of F. fusca and RWA was not confirmed by modelling (GLMM, Fig. 3), it is possible that the distance effect synchronizes the distribution of $F$. fusca and RWA. However, this issue needs further research.

The presence of RWA had a confirmed, strong negative effect only on Lasius platythorax. In the case of spiders, the negative effect was nearly significant, whereas in the case of Myrmica species, a positive effect was recorded. Moreover, the general additive model indicates that the number of species per plot seems to increase with the increasing abundance of the RWA (Fig. 2). Therefore, this study did not provide evidence for a negative effect of RWA on the epigeic invertebrate community. This is surprising in the light of former investigations indicating
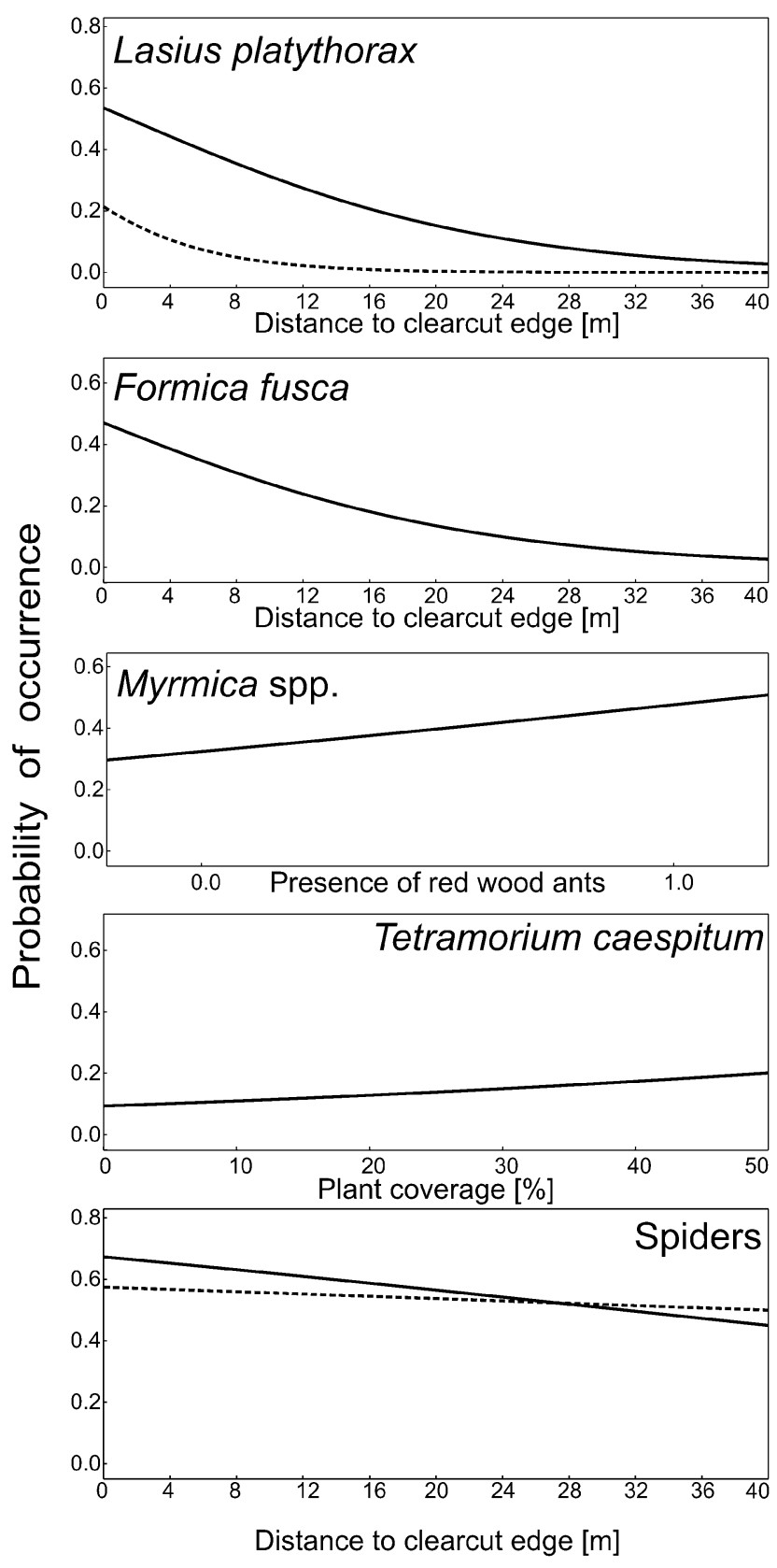

Fig. 3. Probability of occurrence of the arthropods investigated at 276 plots on the clear-cut areas studied in western Poland. In each subplot, the logistic fit of probability of occurrence (y-axis) is presented in relation to the explanatory variable (x-axis). For subplots with two lines, dashed lines represent plots with red wood ants, whereas solid lines those without red wood ants.

a strong effect of RWA on epigeic invertebrates (Kajak et al., 1972; Niemelä et al., 1992; Laakso, 1999; Hawes et al., 2002; Reznikova \& Dorosheva, 2004; Dorosheva \& Reznikova, 2006; but see also Lenoir et al., 2003). It is possible that specific abiotic factors of clear-cut areas (e.g. decrease in the abundance of aphids, increase in insolation) and the high dynamics of the ecosystem, typical of early successional stages, significantly weaken the inter-specific interactions (e.g. competition) that occur 
in more stable habitats. As a consequence, the interactions between red wood ants and other ground arthropods inhabiting clear-cut areas observed in this study are not very pronounced.

The negative effect of clear-cutting (expressed as distance to the edge of a clear-cut area) was evident in the case of Lasius platythorax, Formica fusca and spiders. Also, RWA occur significantly more often in plots close to the edge, compared to those close to the centre of clear-cut areas. This shows that clear-cutting strongly affects ground dwelling arthropods and greatly changes the community. This also indicates that most of the arthropods studied may be avoiding the abiotic conditions characterizing the central parts of clear-cut areas. In general, these findings are similar to those of previous studies (Sorvari \& Hakkarainen, 2005, 2007; Arnan et al., 2007; Niemelä et al., 2007; Matveinen-Huju \& Koivula, 2008, Żmihorski, 2010, but see also Dekoninck et al., 2010). Nevertheless, avoidance of the centers of clear-cut areas by the arthropods investigated may lead to important implications for forest management. The results show that the arthropods studied are not distributed evenly in clear-cut areas and occurred at higher densities close to the intact forest. Therefore, the shape and size of a clear-cut area may significantly influence its usefulness for a given species (e.g. Koivula \& Niemelä, 2003; Matveinen-Huju et al., 2006; Niemelä et al., 2007). In the case of most of the arthropods studied, small and/or irregular clear-cut areas should provide better habitat conditions than large ones. It is also possible that single trees or small groups of trees left on clear-cut areas to maintain forest biodiversity (Matveinen-Huju et al., 2006; Rosenvald \& Lõhmus, 2008) may, like the forest edge, increase local densities of ground arthropods. However, the above conclusions are not based on the analysis of a big data set and need to be verified in the future.

The abundance of RWA decreases towards the centers of clear-cut areas and therefore one may expect that this decrease leads to an increase in the density of other invertebrates that are the prey and/or compete with RWA. The central parts of clear-cut areas in managed forests, are enemy-free space, and may therefore be characterised by higher species richness and higher diversity of many antsensitive invertebrates, as compared to the edges of clear-cut areas and mature forest. However, the results obtained in this study do not support this hypothesis. In this study the distance to the edge of a clear-cut area had a much more pronounced effect than RWA. This indicates that, in general, ground dwelling arthropods are more abundant in habitats close to the forest edge that are utilized also by RWA than RWA-free sites located in the central part of a clear-cut area.

ACKNOWLEDGEMENTS. I am grateful to K. Matveinen-Huju and to P. Ślipiński and to two anonymous reviewers for helpful comments on previous versions of the manuscript. The study was partially supported by the Polish Ministry of Science and Higher Education (grant no. N304 040 32/1895). B. Przybylska kindly improved the English.

\section{REFERENCES}

Arnan X., Rodrigo A. \& Retana J. 2007: Uncoupling the effects of shade and food resources of vegetation on Mediterranean ants: an experimental approach at the community level. Ecography 30: 161-172.

AtLegrim O. 2005: Indirect effects of ant predation (Hymenoptera: Formicidae) on bilberry Vaccinium myrtillus. Eur. J. Entomol. 102: 175-180.

Bolker B.M., Brooks M.E., Clark C.J., Geange S.W., Poulsen J.R., Stevens M.H.H. \& White J.-S.S. 2009: Generalized linear mixed models: a practical guide for ecology and evolution. Trends Ecol. Evol. 24: 127-135.

Czechowski W., Radchenko A. \& Czechowska W. 2002: The ants (Hymenoptera, Formicidae) of Poland. Museum and Institute of Zoology PAS, Warszawa, $200 \mathrm{pp}$.

Dekoninck W., Hendrickx F., Grootaert P. \& Maelfait J.P. 2010: Present conservation status of red wood ants in northwestern Belgium: Worse than previously, but not a lost cause. Eur. J. Entomol. 107: 209-218.

Dorosheva E.A. \& ReznIKova Z.I. 2006: Behavioral mechanisms of spatial competition between red wood ants (Formica aquilonia) and ground beetles (Carabidae). Zh. Obshch. Biol. 67: 344-360.

Geiselhardt S.F., Peschke K. \& Nagel P. 2007: A review of myrmecophily in ant nest beetles (Coleoptera: Carabidae: Paussinae): linking early observations with recent findings Naturwissenschaften 94: 871-894.

Hawes C., Stewart A.J.A. \& Evans H.F. 2002: The impact of wood ants (Formica rufa) on the distribution and abundance of ground beetles (Coleoptera: Carabidae) in a Scots pine plantation. Oecoloogia 131: 612-619.

Jäntti A., Suorsa P., Hakkarainen H., Sorvari J., Huhta E. \& KuItunEn M. 2007: Within territory abundance of red wood ants Formica rufa is associated with the body condition of nestlings in the Eurasian treecreeper Certhia familiaris. $J$. Avian Biol. 38: 619-624.

Kajak A., Breymeyer A., Pętal J. \& Olechowicz E. 1972: The influence of ants on the meadow invertebrates. Ekol. Pol. 20: 163-171.

Kilpeläinen J., Punttila P., Finér L., Niemelä P., Domisch T., Jurgensen M.F., Neuvonen S., Ohashi M., Risch A.C. \& SunDSTRÖM L. 2008: Distribution of ant species and mounds (Formica) in different-aged managed spruce stands in eastern Finland. J. Appl. Entomol. 132: 315-325.

Koivula M. \& Niemelä J. 2003: Gap felling as a forest harvesting method in boreal forests: responses of carabid beetles (Coleoptera, Carabidae). Ecography 26: 179-187.

LAAKSO J. 1999: Short-term effects of wood ants (Formica aquilonia Yarr.) on soil animal community structure. Soil Biol. Biochem. 31: 337-343.

Lambrechts M.M., Schatz B. \& Bourgault P. 2008: Interactions between ants and breeding Paridae in two distinct Corsican oak habitats. Folia Zool. 57: 264-268.

Lenoir L., Bengtsson J. \& Persson T. 2003: Effects of Formica ants on soil fauna-results from a short-term exclusion and a long-term natural experiment. Oecologia 134: 423-430.

LePš J. \& ŠMilauer P. 2003: Multivariate Analysis of Ecological Data using CANOCO. Cambridge University Press, Cambridge, $282 \mathrm{pp}$.

LinDER P. \& ÖsTLUND L. 1998: Structural changes in three midboreal Swedish forest landscapes, 1885-1996. Biol. Conserv. 85: 9-19.

Matveinen-Huju K. \& Koivula M. 2008: Effects of alternative harvesting methods on boreal forest spider assemblages. Can. J. For. Res. 38: 782-794. 
Matveinen-Huju K., Niemelä J., Rita H. \& O’Hara R.B. 2006 : Retention-tree groups in clear-cuts: Do they constitute "lifeboats" for spiders and carabids? Forest Ecol. Manag. 230: $119-135$.

Niemelä J., Haila Y., Halme E., Pajunen T. \& Punttila P. 1992: Small-scale heterogeneity in the spatial distribution of carabid beetles in the southern Finnish taiga. J. Biogeogr. 19: $173-181$.

Niemelä J., Koivula M. \& Kotze D.J. 2007: The effects of forestry on carabid beetles (Coleoptera: Carabidae) in boreal forests. J. Insect Conserv. 11: 5-18.

PisARSKI B. \& VePsäläInEN K. 1989: Competition hierarchies in ant communities (Hymenoptera, Formicidae). Ann. Zool. 42: 321-328.

Punttila P., Haila Y. \& Tukia H. 1996: Ant communities in taiga clearcuts: habitat effects and species interactions. Ecography 19: 16-28.

R Development Core Team 2009: R: A Language and Environment for Statistical Computing. R Foundation for Statistical Computing, URL http://www.R-project.org.

ReZnikova Z. \& Dorosheva H. 2004: Impacts of red wood ants Formica polyctena on the spatial distribution and behavioural patterns of ground beetles (Carabidae). Pedobiologia 48: $15-21$.
Rosenvald R. \& LõHmus A. 2008: For what, when, and where is green-tree retention better than clear-cutting? A review of the biodiversity aspects. Forest Ecol. Manag. 255: 1-15.

Servigne P. \& Detrain C. 2008: Ant-seed interactions: combined effects of ant and plant species on seed removal patterns. Insectes Soc. 55: 220-230.

SORVARI J. \& HaKKaRAINEN H. 2005: Deforestation reduces nest mound size and decreases the production of sexual offspring in the wood ant Formica aquilonia. Ann. Zool. Fenn. 42: 259-267.

Sorvari J. \& HaKKarainen H. 2007: Wood ants are wood ants: deforestation causes population declines in the polydomous wood ant Formica aquilonia. Ecol. Entomol. 32: 707-711.

VÄÄNÄNEn S., SAVolainen R. \& VepsäläINEN K. 2010: Indirect effects in boreal ant assemblages: territorial wood ants protect potential slaves against enslaving ants. Ann. Zool. 60: 57-67.

WesOŁOWSKI T. 2005: Virtual conservation: How the European Union is turning a blind eye to its vanishing primeval forest. Conserv. Biol. 19: 1349-1358.

WŁODARCZYK T., ŻMIHORSKI M. \& OlCZYK A. 2009: Ants inhabiting stumps on clearcuts in managed forest in western Poland. Entomol. Fenn. 20: 121-128.

ŻMIHORSKI M. 2010: Distribution of red wood ants (Hymenoptera: Formicidae) in the clear-cut areas of a managed forest in Western Poland. J. Forest Res. 15: 145-148.

Received August 12, 2010; revised and accepted January 11, 2011 